\title{
Chlorpromazine induced priapism : An up to date mini-review
}

\author{
Review \\ Mohamed Ahmed Abd El Salam \\ Article \\ Department of Andrology, Sexology and STDs, Faculty of Medicine, Cairo University, \\ Giza, Egypt
}

\begin{abstract}
Priapism is an andrological emergency that is characterized by persistent penile erection for more than $4 \mathrm{~h}$ that is not related to sexual arousal and requires urgent intervention to preserve the erectile ability of corpora cavernosa. Iatrogenic priapism or drug-induced priapism is considered as a clinically relevant cause of veno-occlusive priapsim that is commonly caused by the administration of a certain drug or as an interaction with other drugs. Several causes have been attributed to cause such condition including the use of antipsychotic drugs as chlorpromazine. Chlorpromazine is a widely used inexpensive antipsychotic that is almost safe, but it has some encountered adverse effects including priapism. Only few cases have been reported in literature concerning priapism as an adverse effect of chlorpromazine; however, most of them were owing to overdose, prolonged administration or as an interaction with other drugs. Here, in this mini-review, we discuss the chlorpromazine-induced priapisms that have been reported in literature.
\end{abstract}

Key Words: Antipsychotic, chlorpromazine, iatrogenic, veno-occlusive, priapism

Received: 21 December 2017, Accepted: 12 March 2018

Corresponding Author: Mohamed Ahmed Abd El Salam, MD, (9) Montaser Buildings, St. Gamal Abd El Naser, Hadayek Helwan, Cairo 11732, Egypt Tel.: 20223756 219, E-mail: moh_756@yahoo.com; moh_756@cu.edu.eg

ISSN: 2090-6048, March 2018, Vol. 8, No. 1

\section{PRIAPSIM DEFINITION AND CAUSES}

Priapism is a rare andrological emergency characterized by prolonged penile erection that persists for more than $4 \mathrm{~h}$ that is not related to sexual stimulation. It is mainly classified into three main types: ischemic (low flow or veno-occlusive) priapism, arterial (high flow or nonischemic) priapism, and stuttering (recurrent or intermittent) priapism ${ }^{[1]}$.

Ischemic priapism is considered as the most common type of priapism (accounting for $>95 \%$ of cases) that is due to obstruction of venous outflows from leading to impaired perfusion of cavernous tissue with subsequent hypoxia, hypercapnia and acidosis, ending in fibrosis and erectile dysfunction. Several causes have been attributed to cause ischemic priapism including hemoglobinopathies (including sickle cell anemia and thalassemias), hypercoagulable status, neoplastic syndromes, compressive pelvi-abdominal masses, and spinal cord injuries. In addition, the use of some drugs may lead to iatrogenic veno-occlusive priapism including use of some recreational drugs (cocaine, heroin, opiates, and cannabis) and medications (intracavernosal injections of papaverine, phentolamine, and prostaglandin E1, anticoagulants, $\alpha$-blockers, antidepressants, and antipsychotics). However, ischemic priapism has been identified as idiopathic in most cases as no specific cause could be identified. Urgent management of ischemic priapism with aspiration/ irrigation along with the use of sympathomimetic agents gives better outcome. However, if left untreated, resolution may take days and erectile dysfunction invariably results that may require penile prosthesis implantation ${ }^{[2]}$.

On the contrary, nonischemic priapism may results from penile or perineal or pelvic traumas that cause laceration in the cavernosal, perineal, or pudendal artery leading to a high-flow fistula between the artery and the lacunar spaces of the sinusoidal tissue. In addition, pelvic and perineal surgeries may precipitate in such condition. Nonischemic priapism is characterized by less rigid nonpainful penile erection and less damage of the erectile cavernous tissue. Management of such cases includes conservative therapy and angiography with embolization of the fistulous connections ${ }^{[3]}$.

Finally, the stuttering priapism is rare and poorly understood type of priapism. It is characterized by recurrent attacks of prolonged penile erection that usually resolve spontaneously. The etiology of stuttering priapism is similar to that of ischemic priapism; however, sickle cell disease is the most common cause. The cause can also be idiopathic and rarely owing to a neurological disorder. Interventions for this type of recurrent problem include aggressive blockade of testosterone with ketoconazole (which requires supplementation of corticosteroids to prevent adrenal insufficiency), antiandrogens and luteinizing hormone-releasing hormone agonists, low dose of phosphodiesterase type 5 inhibitors, and self-injections of sympathomimetics ${ }^{[4]}$. 


\section{PSYCHOTROPIC MEDICATIONS AND} PRIAPISM

Nowadays, antipsychotic drugs are widely used in clinical practice to manage several psychiatric and personality disorders. Iatrogenic priapism has been mentioned in literature as an adverse effect of these antipsychotics, which accounts for $15-26 \%$ of druginduced priapism. Several antipsychotics have been reported to cause iatrogenic priapism including amisulpride, aripiprazole, chlorpromazine, clozapine, olanzapine, quetiapine, thiothexene, thioridazine, and risperidone ${ }^{[5]}$.

\section{CHLORPROMAZINE AND PRIAPISM}

Chlorpromazine is a widely used and inexpensive typical (first-generation) antipsychotic that belongs to aliphatic phenothiazine family. It has been listed as one of the top ranked essential drugs listed by the WHO in treatment of psychotic disorders as schizophrenia. Its exact mechanism of action is not fully understood; however, it was believed to have dopamine antagonist effect. In addition, it also has antiserotonergic and antihistaminergic properties and peripheral $\alpha$-blocking effect. Several adverse effects of chlorpromazine have been mentioned in literature including common adverse effects such as movement problems, sleepiness, dry mouth, orthostatic hypotension, and increased body weight. In addition, less common serious adverse effects may include tardive dyskinesia, neuroleptic malignant syndrome, seizures, agranulocytosis, and priapism ${ }^{[6]}$.

Concerning the exact mechanism by which chlorpromazine causes priapism is still not clarified; however, it was suggested that it may be because of peripheral $\alpha-1$ blockade and central serotonin-like actions of this agent. Only few reported cases have been mentioned in literature on chlorpromazine-induced priapism and most of them were due to overdose, long-term therapy of psychiatric illness ${ }^{[7,8]}$ or interaction as well as combined use of antipsychotics with other psychostimulants, antidepressants, and mood stabilizers as risperidone, quetiapine, methylphenidate, and trazadone ${ }^{[9,10]}$.

Although the dose of chlorpromazine that causes priapism is still controversial, it is not considered to be a dose-specific complication. Only very few reported cases have mentioned the occurrence of priapism following the administration of single dose of chlorpromazine. On 1977, Merkin ${ }^{[11]}$ had reported that a patient had developed priapism following the administration of a single dose of chlorpromazine for the treatment of remittent hiccups. The other unusual case report by Jackson and Walker ${ }^{[12]}$, mentioned that a 36-year-old patient developed priapism after inserting a crushed $25-\mathrm{mg}$ chlorpromazine tablet into the urethral meatus of his penis.
In addition, Suleekwe ${ }^{[13]}$ reported a young Nigerian patient who developed priapism following the administration of a single dose of chlorpromazine, and detumesence was achieved by needle aspiration. Turkan et al. ${ }^{[14]}$ have also reported two cases of neglected priapism shortly following the administration of a single oral dose of chlorpromazine. Both were refractory to aspiration/ irrigation with diluted adrenaline and subsequently managed with distal corporo-spongial T-shunt and detumesence was obtained. Later on, they had semirigid penile prosthesis implantation owing to residual erectile dysfunction in the follow-up visits. Recently, Abd El Salam and Foaad ${ }^{[15]}$ have reported a 23-year-old male who was presented with neglected priapism after administration of a single oral dose of chlorpromazine $100 \mathrm{mg}$ and was managed with urgent semi-rigid penile prosthesis implantation to avoid extensive cavernosal fibrosis and easy placement of the implant.

\section{CONCLUSION}

Chlorpromazine is a commonly used psychotropic drug being prescribed in clinical practice for treatment of psychotic disorders as schizophrenia. Generally, it is costeffective and safely prescribed; however, some adverse effects have been reported, including priapism. Most of cases are either due to overdose, prolonged therapy, and sudden discontinuation or due to interaction with other drugs. Very few reported cases were due to singular dose of chlorpromazine. Thus, physicians must be alert and oriented about this uncommon andrological emergency. In addition, early diagnosis and rapid management of such cases could lead to favorable prognosis and better outcome preserving the erectile ability of corpora cavernosa.

\section{CONFLICT OF INTEREST}

There are no conflicts of interest.

\section{REFERENCES}

1. Shigehara K, Namiki M. Clinical management of priapism: a review. World J Mens Health 2016; 34:1.

2. Tay Y, Spernat D, Rzetelski-West K, Appu S, Love C. Acute management of priapism in men. BJU Int 2012; 109:15-21.

3. Hatzichristou D, Salpiggidis G, Hatzimouratidis K, Apostolidis A, Tzortzis V, Bekos A, Saripoulos D. Management strategy for arterial priapism: therapeutic dilemmas. J Urol 2002; 168:2074-2077.

4. Kheirandish P, Chinegwundoh F, Kulkarni S. Treating stuttering priapism. BJU Int 2011; 108:1068-1072. 
5. Reeves R, Mack J. Priapism associated with two atypical antipsychotic agents. Pharmacotherapy 2002; 22:1070-1073.

6. Solmi M, Murru A, Pacchiarotti I, Undurraga J, Veronese N, Fornaro M, et al. Safety, tolerability, and risks associated with first- and second-generation antipsychotics: a state-of-the-art clinical review. Ther Clin Risk Manag 2017; 13:757-777.

7. Kilciler M, Bedir S, Sümer F, Dayanç M, Peker A. Priapism in a patient receiving long-term chlorpromazine therapy. Urol Int 2003; 71:127-128.

8. Andersohn F, Schmedt N, Weinmann S, Willich S, Garbe E. Priapism associated with antipsychotics. J Clin Psychopharmacol 2010; 30:68-71.

9. Eslami Shahrbabaki M, Sabzevari L. Early onset priapism under chlorpromazine and risperidone therapy. Iran J Psychiatry Behav Sci 2011; 5:139-142.
10. Baytunca M, Kose S, Ozbaran B, Erermis S. Risperidone, quetiapine and chlorpromazine may have induced priapism in an adolescent. Pediatr Int 2015; 58:61-63.

11. Merkin T. Priapism as a sequel of chlorpromazine therapy. JACEP 1977; 6:367-368.

12. Jackson S, Walker J. Self-administered intraurethral chlorpromazine: an unusual cause of priapism. Am J Emerg Med 1991; 9:171-175.

13. Suleekwe E. Priapism after a singular dose of chlorpromazine. Ann Biomed Sci 2011; 10:1.

14. Turkan S, Kalkan M, Şahin C. Two priapism cases following short-term use of chlorpromazine. J Clin Anal Med 2014; 5:47-48.

15. Abd El Salam M, Foaad H. Chlorpromazine induced priapism from a single dose: an unusual complication of antipsychotic agent. Russ Open Med J 2017; 6:e0306. 